\title{
How far do tadpoles travel in the rainforest? Parent-assisted dispersal in poison frogs
}

\author{
Andrius Pašukonis $^{1,2}$ (D) Matthias-Claudio Loretto ${ }^{2}$ (D) $\cdot$ Bibiana Rojas $^{3}$ (D)
}

Received: 23 February 2019 / Accepted: 5 June 2019 / Published online: 5 July 2019

(c) The Author(s) 2019

\begin{abstract}
Parents can influence offspring dispersal through breeding site selection, competition, or by directly moving their offspring during parental care. Many animals move their young, but the potential role of this behavior in dispersal has rarely been investigated. Neotropical poison frogs (Dendrobatidae) are well known for shuttling their tadpoles from land to water, but the associated movements have rarely been quantified and the potential function of tadpole transport in dispersal has not been addressed. We used miniature radiotransmitters to track the movements of two poison frog species during tadpole transport, and surveyed pool availability in the study area. We found that parental males move farther than expected by the distance to the nearest pool and spread their offspring across multiple pools. We argue that these movement patterns cannot be fully explained by pool quality and availability, and suggest that adaptive benefits related to offspring dispersal also shape the spatial behavior of parental frogs.
\end{abstract}

Keywords Informed dispersal $\cdot$ Parental care $\cdot$ Tadpole transport $\cdot$ Resource use · Dendrobatidae

\section{Introduction}

The local physical and social environment can have a strong influence on animal dispersal (i.e., context-dependent dispersal, Bowler and Benton 2005; Matthysen 2012). Dispersing individuals may integrate the environmental factors experienced at the present and learned in the past (informed dispersal sensu Clobert et al. 2009), resulting in complex movement strategies. Adults are usually more experienced than their offspring, but dispersal is more

Electronic supplementary material The online version of this article (https://doi.org/10.1007/s 1068 2-019-09994-z) contains supplementary material, which is available to authorized users.

Andrius Pašukonis

apasukonis@stanford.edu

1 Department of Biology, Stanford University, 371 Serra Mall, Stanford, CA 94305, USA

2 Department of Cognitive Biology, University of Vienna, Althanstrasse 14, 1090 Vienna, Austria

3 Department of Biological and Environmental Sciences, University of Jyväskylä, PO Box 35, 40014 Jyväskylä, Finland 

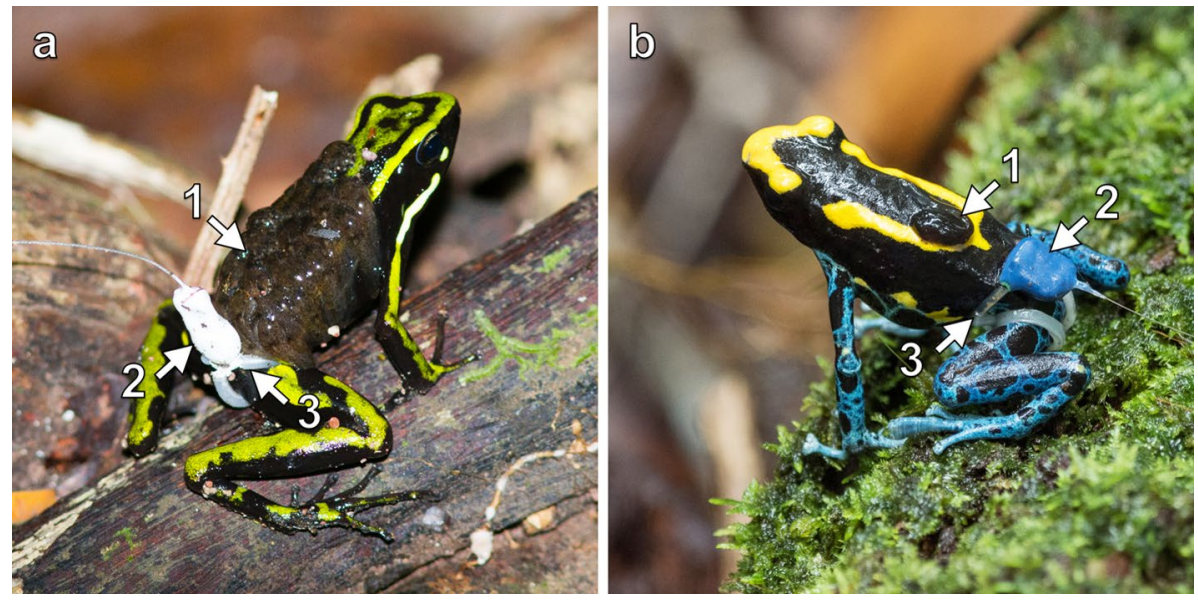

Fig. 1 Photographs of the two study species: a Ameerega trivittata and b Dendrobates tinctorius transporting tadpoles while wearing a radio-transmitter. Ameerega trivittata typically transports 15-30 tadpoles while D. tinctorius only transport one or two tadpoles. The numbers and arrows indicate: (1) tadpoles, (2) radio-transmitter, and (3) a silicone waistband for attachment. (Color figure online)

common in early life stages (Clobert et al. 2012). Parents, however, can influence subsequent offspring dispersal by evaluating and choosing breeding sites and by directly moving offspring during parental care (Bonte et al. 2007; Matthysen et al. 2010; Clobert et al. 2012). For example, female wolf spiders show greater mobility while carrying spiderlings, thus influencing offspring natal dispersal patterns and potentially reducing kin competition (Bonte et al. 2007). Animals as diverse as arachnids and mammals carry their young to protect them during their most vulnerable stage (e.g., Ross 2001; Wolff et al. 2015). Offspring transport may also promote adaptive movement strategies that favor offspring dispersal. While factors such as habitat selection, inbreeding avoidance, and kin-competition are at the core of dispersal theory, the role of parental mobility in offspring dispersal has received little attention so far.

The transport of eggs, tadpoles, and froglets is widespread in anuran amphibians, especially in Neotropical poison frogs (Dendrobatidae) (Wells 2007). Poison frogs are terrestrial and lay their eggs on land, a common strategy among tropical amphibians, presumably shaped by aquatic predator avoidance (Magnusson and Hero 1991; Duellman and Trueb 1994). However, most poison frog tadpoles are aquatic and thus need to be taken by one of their parents from land to water (Fig. 1). Depending on the species, tadpoles are carried by males or females, singly or in groups, and released in terrestrial or arboreal pools ranging from large streams to small water-filled plants (reviewed in Summers and McKeon 2004; Wells 2007). This diversity of parental behaviors has been primarily viewed as a result of trade-offs between water volume-dependent food availability and predation risk inside the pools (Weygoldt 1987; Summers and McKeon 2004; Brown et al. 2010; Summers and Tumulty 2013). Tadpole transport allows parents to make flexible decisions when choosing the best microhabitat for their offspring (Summers and McKeon 2004; Brown et al. 2009; Ringler et al. 2018). In addition, it allows frogs to disperse their offspring over large areas and distribute them among multiple sites (Erich et al. 2015; Beck et al. 2017). Similar to other forms of dispersal (for a review see Bowler and Benton 2005), the benefits of tadpole transport may also include the colonization of new areas, reduced kin competition 
and inbreeding, and the spread of risks between multiple resources. However, the role of tadpole transport in dispersal has been rarely addressed. In this study, we aim to highlight that offspring dispersal could play an important role in shaping parental spatial behavior in poison frogs, and possibly in other taxa that transport their young.

We used miniature radio-transmitters to track parental frog movements during tadpole transport in two poison frog species with male parental care, but otherwise contrasting reproductive strategies. We were particularly interested in establishing whether the frogs use the nearest pool available. Tadpole transport requires energy and time, and may increase exposure to predators and reduce mating opportunities (Beck et al. 2017; Ringler et al. 2013; Wells 2007; this study). Therefore, males should try to minimize the distance and duration of tadpole transport unless there are direct benefits of traveling farther. However, if the benefits related to active offspring dispersal have shaped the spatial behavior of poison frog parents, we would expect more complex movement patterns to emerge.

\section{Methods}

\section{Study species and sites}

We radio-tracked tadpole transporting males of two poison frog species, Ameerega trivittata (Three-striped poison frog, abbreviated as At for methods and results) and Dendrobates tinctorius (Dyeing poison frog, abbreviated as Dt for methods and results). Both species are diurnal, breed throughout the rainy season, and are locally common but allopatric throughout most of their range (AmphibiaWeb 2019). In both species, males transport tadpoles from home territories to water and return back to them after tadpole transport (Silverstone 1975, 1976; Roithmair 1994a, b; Rojas 2014, 2015; Rojas and Pašukonis 2019; this study). The two species differ significantly in other aspects of their reproductive behavior. Ameerega trivittata males call and defend small territories where mating takes place (Roithmair 1994a, b). Clutches of $\sim 40$ eggs are laid in the leaf-litter where they develop for 15-22 days before the male transports tadpoles simultaneously to small terrestrial pools and streams (Acioli and Neckel-Oliveira 2014; Roithmair 1994a, b; this study Fig. S1a-c). Tadpoles are omnivorous and several hundred tadpoles can be found in a single pool (Luiz et al. 2015). In captivity, tadpoles metamorphose after 40-90 days and frogs reach maturity within 1 year (Lötters et al. 2007). Dendrobates tinctorius males show aggressive behavior but lack loud advertisement calls and do not always defend exclusive areas (Born et al. 2010; Rojas and Pašukonis 2019). In our study area, pairs lay small clutches of 2-5 eggs. After $\sim 15$ days of development, males shuttle 1 or 2 tadpoles simultaneously to small pools formed in palm bracts or tree-holes at variable heights (Rojas 2014, 2015; this study Fig. S1d-f). Tadpoles are primarily carnivorous and cannibalistic, and typically less than 10 tadpoles are found in one pool (Rojas 2014, 2015). In the field, tadpoles metamorphose after approximately 2 months (B. Rojas, pers. obs.) and take up to 18 months to mature in captivity (Lötters et al. 2007).

Data for At were collected around the onset of the rainy season in October and November 2014, at the Panguana Biological Field Station inside "Área de Conservación Privada Panguana" on the lower Río Llullapichis, Amazonian Peru ( $\left.9^{\circ} 35^{\prime} \mathrm{S}, 74^{\circ} 48^{\prime} \mathrm{W}\right)$. We monitored an area of approximately 30 ha of rainforest bordering a pastureland on one side. We mapped all terrestrial water bodies found during our study with a GPS/GIS device (MobileMapper 10; Ashtech/Spectra Precision) and ArcPAD 10 (ESRI) software. Some 


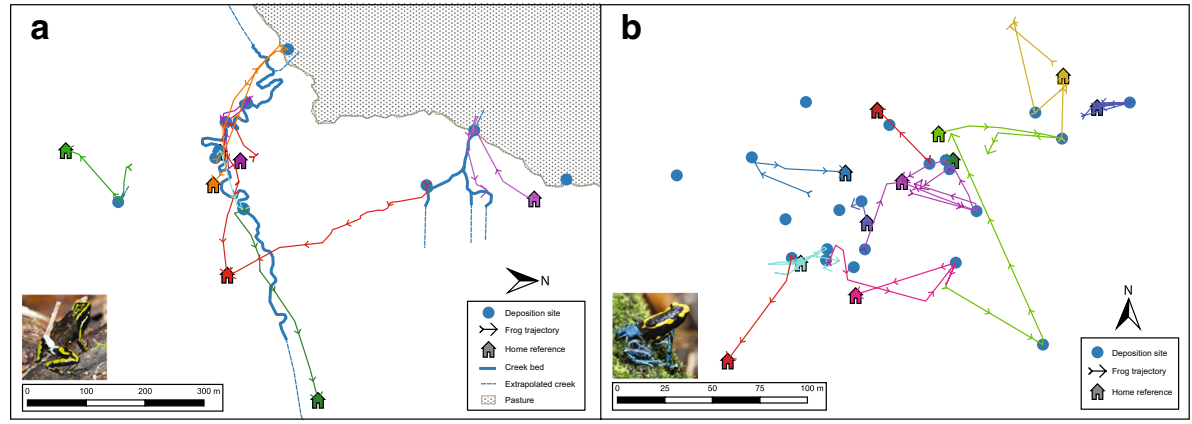

Fig. 2 Map of the study area showing the movements during the tadpole transport of a seven A. trivittata males and b 11 D. tinctorius males. Blue circles represent confirmed tadpole deposition sites; house symbols represent approximated start location of the tadpole transport; each line corresponds to a transport event and each color represents a different individual. a Blue solid and dashed lines mark creek beds, which provided most deposition sites; dotted area corresponds to the forest edge. The shown trajectories do not represent complete movement patterns because some frogs were first detected already outside their home areas and near the deposition sites. Note the difference in map scales between the two species. (Color figure online)

stream sections were not accessible and were mapped by extrapolating mapped parts of the stream. Water bodies were found opportunistically, mostly when tracking tadpoletransporting frogs. Most water bodies consisted of series of partially separated pools in the stream bed that were intermittently connected by flowing water after heavy rainfalls (Fig. 2). Because of the proximity and connectivity of individual pools, the entire stream beds were considered as a tadpole deposition sites. We observed frogs using all mapped water bodies, except for one larger permanent pond, which was excluded from the analysis.

Data for Dt were collected during the mid-rainy season in February-March 2016 and 2017 near the Camp Pararé field site at the CNRS Nouragues Ecological Research Station in the Nature Reserve Les Nouragues, French Guiana $\left(4^{\circ} 02^{\prime} \mathrm{N}, 52^{\circ} 41^{\prime} \mathrm{W}\right)$. We monitored an area of approximately 4 ha of terra-firme rainforest. We mapped all visible water bodies and trees that were climbed by tadpole-transporting frogs. All pools visited by frogs that were accessible for inspection contained tadpoles of Dt and were considered as suitable tadpole deposition sites. In addition, we considered all trees that were climbed by tadpoletransporting frogs as potential deposition sites. Dendrobates tinctorius plot was sampled more evenly than At plot because of the smaller study area, more open understory, and longer study period. However, because Dt primarily use small pools above the ground, the pools were harder to detect and most deposition sites were detected only by tracking tadpole-transporting frogs.

\section{Tagging and tracking}

Ameerega trivittata males $(\mathrm{n}=9)$ were all captured during tadpole transport. One frog was recaptured on two consecutive tadpole transport events. Dendrobates tinctorius males were captured either during tadpole transport $(n=5)$ or were already tagged before tadpole transport $(n=6)$ as part of another study. From these $11 \mathrm{Dt}$ males, two frogs were observed on two and three consecutive transport events. One individual was tracked on two different years. Frogs were kept inside a plastic bag or a net-cage for 15 to $105 \mathrm{~min}$ for the preparation and fitting of the transmitter, but handled only for a few minutes at a time. Frogs were 
equipped with miniature radio transmitters (BD2X, Holohil Systems Ltd.; NTQ2, Lotek Wireless Inc.; PicoPip, Biotrack Ldt; V5, Telemetrie-Service Dessau) attached externally using a waistband or a harness made of silicone materials (Fig. 1; Supplementary video). The tags constituted approximately $10 \%$ of the total frog weight (Dt: frog weight 3.5-4.2 g, tag weight $0.35-0.4 \mathrm{~g}$; At: frog weight $3.8-5.6 \mathrm{~g}$, tag weight $0.36-0.5 \mathrm{~g}$ ). After release, the frogs were located 2 to 12 times a day during the daylight hours using a portable radiotracking receiver (Sika, Biotrack Ltd.) and a flexible Yagi-antenna (Biotrack Ltd.).

We considered a tadpole transport event to be over after a frog deposited all tadpoles and returned back to their presumed home territory after which the frog showed no directional movement for at least $24 \mathrm{~h}$. One At was predated by a snake after tadpole deposition (Fig. S2). In two cases tracking was terminated due to skin injuries from tag attachment. The mapping was done using a combination of GPS and local references established with traditional survey methods (see Ringler et al. 2016). The estimated relative GPS error was approximately 5-8 $\mathrm{m}$. For smaller scale movements we measured the distance and the direction from the previous location using a compass and a laser distance-meter. All data were recorded using a handheld GPS/GIS device.

\section{Data analysis}

Data analysis and visualization were done in QGIS v2.14 (https://www.qgis.org/) and R statistical software (http://www.R-project.org/). For each tadpole transport event, we calculated (1) total duration, (2) cumulative path length, (3) straight-line distance from home to the farthest tadpole deposition site used (i.e., observed pool distance), and (4) straight-line distance to the nearest identified pool site (i.e., nearest pool distance). We did not quantify the home ranges or territories in this study, but approximated the origin of the tadpole transport by a single location termed "home reference" within the presumed home territory. Because most frogs were first located on the way to or at the pools, we used the last point of their homing trajectory as their home reference (Fig. S3). When the exact starting location of the tadpole transport was known or when homing tracking was terminated prematurely due to predation or injury, we used the first point of the trajectory as the home reference. The distances to pools for each frog were calculated from their respective home references. To estimate the cumulative path travelled for incomplete trajectories, we added the straight-line distance from the last point of the trajectory (i.e., home reference) to the location of the first observation. Because of the incomplete tadpole transport trajectories, the total duration and the distances of the transport are very conservative and likely underestimated. We performed a Mann-Whitney-Wilcoxon Test to compare the total durations, observed pool distance, and cumulative distances between the two species, and a paired Wilcoxon Signed-Rank Test to compare the observed and nearest pool distance for each species.

\section{Results}

We successfully tracked eight At and 15 Dt tadpole transport events (seven and 11 different individuals, respectively) (Fig. 2). Ameerega trivittata males transported 15 to 32 tadpoles (mean $\pm \mathrm{SD}=22.1 \pm 6.2$ ) and deposited them in standing water pools in a partially driedup stream bed $(n=6)$ or flooded meadow on the edge of the forest $(n=2)$. Frogs visited and deposited tadpoles in one or two separate water bodies within a single transport event. 


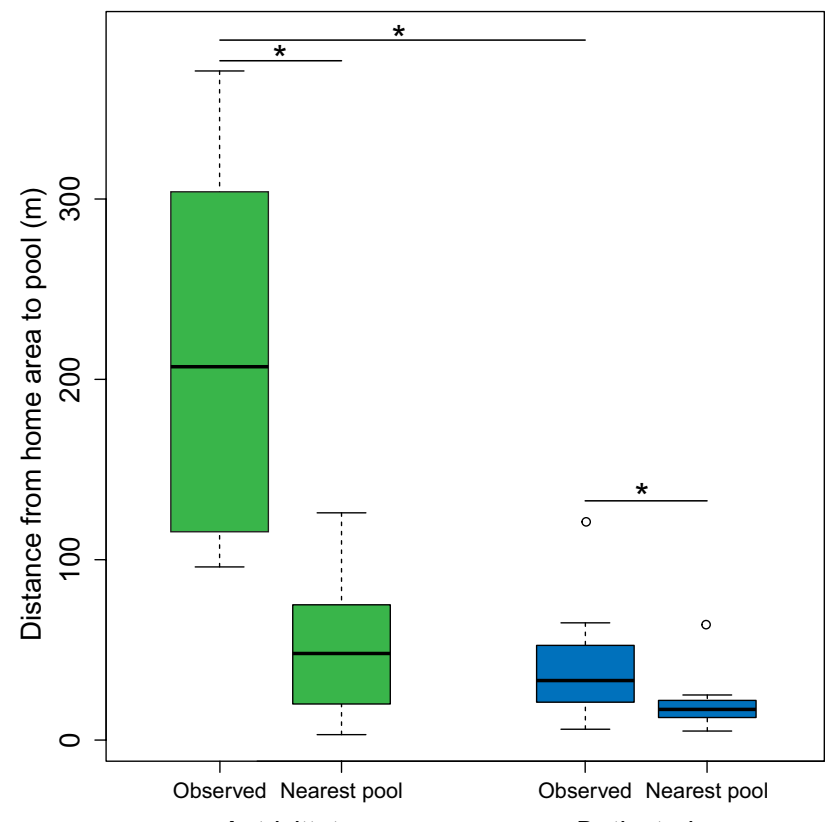

A. trivittata

D. tinctorius

Fig. 3 Boxplot illustrating the difference in distance between the observed tadpole transport distances and the nearest known pool available for each tracked frog and species. Asterisks denote statistically significant differences based on Mann-Whitney-Wilcoxon and Wilcoxon Signed-Rank Tests $(p<0.05)$. (Color figure online)

Dendrobates tinctorius transported 1 to 2 tadpoles and deposited them in water-filled tree holes at $1-10 \mathrm{~m}$ above ground $(\mathrm{n}=5)$, presumed tree holes above $10 \mathrm{~m}$ and thus out of sight $(n=6)$, standing water inside fallen trunks $(n=3)$, and palm bracts $(n=1)$. Dendrobates tinctorius visited up to three deposition sites within one transport event. When transporting two tadpoles $(n=4)$ frogs deposited both tadpoles in the same pool. When the same Dt male was observed during more than one transport event $(n=3)$ frogs deposited tadpoles in different sites during each event.

Ameerega trivittata used tadpole deposition sites farther from home areas than Dt (mean observed distance AT $\pm \mathrm{SD}=215 \pm 109 \mathrm{~m}$, range 96-371 m; mean observed distance $_{\mathrm{DT}} \pm \mathrm{SD}=39 \pm 29 \mathrm{~m}$, range 6-121 m; Wilcoxon test: $\mathrm{W}=118, p<0.001$ ); traveled longer cumulative paths (mean path $\mathrm{AT}_{\mathrm{AT}} \mathrm{SD}=486 \pm 194 \mathrm{~m}$, range $215-766 \mathrm{~m}$; mean path $_{\mathrm{DT}} \pm \mathrm{SD}=109 \pm 63 \mathrm{~m}$, range 17-260 m; Wilcoxon test: $\mathrm{W}=119, p<0.001$ ); and spent longer time away from the home area (mean duration ${ }_{\mathrm{AT}} \pm \mathrm{SD}=79.6 \pm 41.5 \mathrm{~h}$, range 5.9-140 h; mean duration ${ }_{\mathrm{DT}} \pm \mathrm{SD}=14.9 \mathrm{~h} \pm 10.9 \mathrm{~h}$, range $2.5-33.8 \mathrm{~h}$; Wilcoxon test: $\mathrm{W}=108, p=0.001)$.

Males of both species traveled significantly longer distances than the distance to the nearest available pool (mean pool distance ${ }_{\mathrm{AT}} \pm \mathrm{SD}=52 \pm 41 \mathrm{~m}$, range 3-126 m; Wilcoxon paired test: $\mathrm{V}_{\mathrm{AT}}=28, p=0.02$; mean pool distance ${ }_{\mathrm{DT}} \pm \mathrm{SD}=19 \pm 14 \mathrm{~m}$, range 5-64 m; Wilcoxon paired test: $\mathrm{V}_{\mathrm{DT}}=55, p=0.006$; Fig. 3 ). 


\section{Discussion}

Males of both species carried their offspring to several sites farther away than the closest pool available from their respective home areas. The frogs moved directly toward distant pools and sometimes ignored nearby pools that had been used by other individuals even when passing next to them. We thus suggest that patterns of pool availability and quality cannot fully explain the observed movement patterns. We propose that adaptive benefits related to offspring dispersal could also shape the spatial behavior of parental poison frogs.

Resource quality plays an important role in poison frog pool choice (e.g., Brown et al. 2008; McKeon and Summers 2013; Schulte et al. 2013; Ringler et al. 2018), but the assessment of pool quality alone is unlikely to fully account for the large movement extent observed in our study. In most cases, multiple pools were available closer to the home territory, but the frogs did not approach them before moving to more distant pools. Also, frogs ignored some pools that were used by other conspecifics coming from farther away, even when passing in their immediate vicinity. On several occasions, we observed A. trivittata males leaving the forest to deposit tadpoles in a flooded pasture (Fig. 2a), an unusual habitat for a forest species. Dispersal is a key component for understanding the spatial behavior of temperate-region pond-breeding amphibians (Cayuela et al. 2018; Pittman et al. 2014; Sinsch 2014); we propose that parental dispersal in poison frogs might convey adaptive benefits that are important to consider for a better understanding of their behavior.

Dispersing offspring farther than the nearest available pool, and using multiple pools, may entail numerous benefits. Chief among them are reduced competition and inbreeding risk between parents and offspring, and spreading the risk of tadpole predation and pool desiccation, both of which are high in rainforest pools (Magnusson and Hero 1991; Richter-Boix et al. 2011). The use of multiple pools has been reported in other poison frogs (Summers 1990; Brust 1993; Poelman and Dicke 2007; Brown et al. 2008), and experimental studies using artificial pools revealed that males of the poison frog Allobates femoralis remember and use multiple pools over large areas (Erich et al. 2015; Beck et al. 2017; Ringler et al. 2018). A tendency to use new pools whenever they are discovered could gradually produce a spatial pattern where the parent frogs travel farther and farther away from their home areas, which might additionally reduce future competition for mates and territories with their offspring. It is particularly surprising that the territorial males invest so much time in tadpole transport, because leaving the territory unattended may lead both to loss of mating opportunities and loss of the territory to competitors. In addition, movement may increase the predation risk (Paluh et al. 2014; also see observed predation in Fig. S2). The fact that frogs nevertheless travel such long distances suggests that the benefits, which remain to be quantified, outweigh the potential costs.

The reproductive behavior of many tropical frogs has been shaped by a trade-off between larger pools with high predation pressure and small pools with low food availability (Magnusson and Hero 1991; Duellman and Trueb 1994; McKeon and Summers 2013). In response to these trade-offs, some poison frog species became specialists of very small pools and evolved extended parental care, such as egg-feeding (for a review see Summers and McKeon 2004; Brown et al. 2010; Summers and Tumulty 2013). These species appear to have restricted space-use and often hold territories that include tadpole deposition sites (Donnelly 1989; Pröhl and Hödl 1999; Poelman and Dicke 2007; Brown et al. 2009). Many other poison frogs use pools of variable size and do not provide extended parental care, but the factors shaping their behavior are poorly understood. Ancestral poison frogs probably lived close to streams and did not need to travel far for tadpole deposition (Weygoldt 1987; 
Summers and McKeon 2004). Therefore, we speculate that long-distance tadpole transport between multiple terrestrial pools is another derived form of parental care that has been in part shaped by the adaptive benefits of parent-assisted offspring dispersal.

Our results also support the idea that poison frogs have a good spatial knowledge of the surrounding area and probably remember the exact locations of the pools themselves, as demonstrated in previous studies (Pašukonis et al. 2014, 2016, 2018; Beck et al. 2017). The movement trajectories of tadpole carriers were directed to small pools sometimes several hundred meters away from home. Given the well-developed spatial memory and the observed movements patterns, it seems unlikely that frogs were not able to detect the nearby pools and accidentally encountered the distant ones. How frogs discover the small distant pools in the first place remains unknown, but exploration during non-reproductive phases and olfactory cues might play a role (Pašukonis et al. 2016; Beck et al. 2017). We further hypothesize that the highly developed navigational abilities and spatial memory have coevolved with the long-distance shuttling of tadpoles.

Parental mobility may have a strong influence on offspring dispersal in a variety of animals outside poison frogs. Natural history observations suggest that in at least two rainforest frogs from Papua New Guinea (Bickford 2002) and one cave breeding Jamaican frog (Diesel et al. 1995), the transport of fully developed froglets serves a specific dispersal function. Transport of young is also common in arachnids and mammals, while many birds move together with their offspring. It has been long acknowledged that parents influence offspring dispersal decisions through conflict and competition (Motro 1983; Starrfelt and Kokko 2010), but more studies on individual movement patterns might reveal that parental spatial behavior also plays a significant role in offspring dispersal.

Acknowledgements Open access funding provided by Austrian Science Fund (FWF). We are most grateful to Walter Hödl for the mentorship, enthusiasm, and help in the field that made this study possible. We thank Juliane Diller and the Módena family for welcoming us at the Panguana Biological Station and Carl Gerhardt for insightful discussion and help in the field. We also thank Max Ringler, Shirley Jennifer Serrano Rojas, Rosanna Mangione, Philippe Gaucher, and the staff of the Nouragues Ecological research station for help in the field and the logistic support.

Authors' contributions Conceptualization, resources and funding acquisition: AP, MCL, BR; Methodology: AP, MCL; Data collection: AP, MCL; Analysis and the original draft: AP; Review and editing: AP, MCL, BR.

Funding This project was funded by the Austrian Science Fund (FWF) Projects W1234-G17 and J3827-B29, the German Herpetological Society (DGHT, Wilhelm-Peters- Fond 2014), Investissement d'Avenir funds of the ANR (CEBA: ANR-10-LABX-25-01, ANAEE-France: ANR-11-INBS-0001) in the framework of the Nouragues Travel Grant granted to AP and BR; and the research grant from the Association for the Study of Animal Behaviour (ASAB) granted to AP. AP is currently funded by Lauren A. O'Connell with Stanford University funds. MCL is currently funded by the Austrian Science Fund (FWF, Project No. P 29705). BR is currently funded by the Academy of Finland (Academy Research Fellowship, Project No. 21000042021).

\section{Compliance with ethical standards}

Conflict of interest The authors declare that they have no conflict of interest.

Ethical approval The research in Peru was performed under the official research Permit No. 007-2014-SERFOR-DGGSPFFS, given to Dr. Juliane Diller by the Peruvian forestry and nature conservancy authority SERFOR (Servicio Forestal y de Fauna Silvestre). The research in French Guiana was approved by the Animal Welfare Board of the University of Vienna (approval number: 2016-002) and by the scientific committee of the Nouragues Ecological Research Station. The experiments were conducted in strict accordance with the European, French and Peruvian laws and following the 'Guidelines for use of live amphibians and 
reptiles in the field and laboratory research' by the Herpetological Animal Care and Use Committee (HACC) of the American Society of Ichthyologists and Herpetologists (Beaupre et al. 2004); and the Association for the Study of Animal Behaviour (ASAB) Guidelines for the treatment of animals in behavioral research and teaching (Vitale et al. 2018).

Open Access This article is distributed under the terms of the Creative Commons Attribution 4.0 International License (http://creativecommons.org/licenses/by/4.0/), which permits unrestricted use, distribution, and reproduction in any medium, provided you give appropriate credit to the original author(s) and the source, provide a link to the Creative Commons license, and indicate if changes were made.

\section{References}

Acioli ECS, Neckel-Oliveira S (2014) Reproductive biology of Ameerega trivittata (Anura: Dendrobatidae) in an area of terra firme forest in eastern Amazonia. Acta Amazon 44:473-480

AmphibiaWeb (2019) https://amphibiaweb.org, University of California, Berkley, CA, USA. Accessed 17 Jan 2019

Beaupre SB, Jacobson ER, Lillywhite HB, Zamudio K (2004) Guidelines for use of live amphibians and reptiles in field and laboratory research. In: Herpetological Animal Care and Use Committee (HACC), 2nd revised edn. American Society of Ichthyologists and Herpetologists, Lawrence, Kansas, USA

Beck KB, Loretto M-C, Ringler M, Hödl W, Pašukonis A (2017) Relying on known or exploring for new? Movement patterns and reproductive resource use in a tadpole-transporting frog. PeerJ 5:e3745

Bickford D (2002) Male parenting of New Guinea froglets. Nature 418:601-602

Bonte D, Van Belle S, Maelfait J-P (2007) Maternal care and reproductive state-dependent mobility determine natal dispersal in a wolf spider. Anim Behav 74:63-69

Born M, Bongers F, Poelman EH, Sterck FJ (2010) Dry-season retreat and dietary shift of the dart-poison frog Dendrobates tinctorius (Anura: Dendrobatidae). Phyllomedusa J Herpetol 9:37-52

Bowler DE, Benton TG (2005) Causes and consequences of animal dispersal strategies: relating individual behaviour to spatial dynamics. Biol Rev 80:205-225

Brown JL, Twomey E, Morales V, Summers K (2008) Phytotelm size in relation to parental care and mating strategies in two species of Peruvian poison frogs. Behaviour 145:1139-1165

Brown JL, Morales V, Summers K (2009) Home range size and location in relation to reproductive resources in poison frogs (Dendrobatidae): a Monte Carlo approach using GIS data. Anim Behav 77:547-554

Brown JL, Morales V, Summers K (2010) A key ecological trait drove the evolution of biparental care and monogamy in an amphibian. Am Nat 175:436-446

Brust DG (1993) Maternal brood care by Dendrobates pumilio: a frog that feeds its young. J Herpetol 27:96

Cayuela H, Valenzuela-Sanchez A, Teulier L, Martínez-Solano Í, Léna J-P, Merilä, J, Muth E, Shine R, Quay L, Denoël M, Clobert J, Schmidt B (2018) Determinants and consequences of dispersal in vertebrates with complex life cycles: a review of pond-breeding amphibians. PeerJ Preprints 6:e27394v1

Clobert J, Le Galliard J-F, Cote J, Meylan S, Massot M (2009) Informed dispersal, heterogeneity in animal dispersal syndromes and the dynamics of spatially structured populations. Ecol Lett 12:197-209

Clobert J, Baguette M, Benton TG, Bullock MJ (eds) (2012) Dispersal ecology and evolution. Oxford University Press, Oxford

Diesel R, Bäurle G, Vogel P (1995) Cave breeding and froglet transport: a novel pattern of anuran brood care in the Jamaican frog, Eleutherodactylus cundalli. Copeia 1995:354-360

Donnelly MA (1989) Effects of reproductive resource supplementation on space-use patterns in Dendrobates pumilio. Oecologia 81:212-218

Duellman WE, Trueb L (1994) Biology of amphibians. Johns Hopkins University Press, Baltimore

Erich M, Ringler M, Hödl W, Ringler E (2015) Brood-partitioning behaviour in unpredictable environments: hedging the bets? Behav Ecol Sociobiol 69:1011-1017

Lötters S, Jungfer K-H, Henkel FW, Schmidt W (2007) Poison frogs: biology, species and captive husbandry. Serpent's Tale NHBD/Edition Chimaira, London

Luiz LF, Contrera FAL, Neckel-Oliveira S (2015) Diet and tadpole transportation in the poison dart frog Ameerega trivittata (Anura, Dendrobatidae). Herpetol J 25:187-190

Magnusson WE, Hero J-M (1991) Predation and the evolution of complex oviposition behaviour in Amazon rainforest frogs. Oecologia 86:310-318

Matthysen E (2012) Multicausality of dispersal: a review. In: Clobert J, Baguette M, Benton TG, Bullock JM (eds) Dispersal ecology and evolution. Oxford University Press, Oxford, pp 3-18 
Matthysen ET, Van Overveld T, Van de Casteele T, Adriaensen F (2010) Family movements before independence influence natal dispersal in a territorial songbird. Oecologia 162:591-597

McKeon CS, Summers K (2013) Predator driven reproductive behavior in a tropical frog. Evol Ecol 27:725-737

Motro U (1983) Optimal rates of dispersal. III. Parent-offspring conflict. Theor Popul Biol 23:159-168

Paluh DJ, Hantak MM, Saporito RA (2014) A test of aposematism in the dendrobatid poison frog Oophaga pumilio: the importance of movement in clay model experiments. J Herpetol 48:249-254

Pašukonis A, Warrington I, Ringler M, Hödl W (2014) Poison frogs rely on experience to find the way home in the rainforest. Biol Lett 10:20140642

Pašukonis A, Trenkwalder K, Ringler M, Ringler E, Mangione R, Steininger J, Warrington I et al (2016) The significance of spatial memory for water finding in a tadpole-transporting frog. Anim Behav 116:89-98

Pašukonis A, Loretto M-C, Hödl W (2018) Map-like navigation from distances exceeding routine movements in the three-striped poison frog (Ameerega trivittata). J Exp Biol 221:jeb169714

Pittman SE, Osbourn MS, Semlitsch RD (2014) Movement ecology of amphibians: a missing component for understanding population declines. Biol Conserv 169:44-53

Poelman EH, Dicke M (2007) Offering offspring as food to cannibals: oviposition strategies of Amazonian poison frogs (Dendrobates ventrimaculatus). Evol Ecol 21:215-227

Pröhl H, Hödl W (1999) Parental investment, potential reproductive rates, and mating system in the strawberry dart-poison frog, Dendrobates pumilio. Behav Ecol Sociobiol 46:215-220

Richter-Boix A, Tejedo M, Rezende EL (2011) Evolution and plasticity of anuran larval development in response to desiccation. A comparative analysis. Ecol Evol 1:15-25

Ringler E, Pašukonis A, Hödl W, Ringler M (2013) Tadpole transport logistics in a Neotropical poison frog: indications for strategic planning and adaptive plasticity in anuran parental care. Front Zool 10:67

Ringler M, Mangione R, Pašukonis A, Rainer G, Gyimesi K, Felling J, Kronaus H et al (2016) High-resolution forest mapping for behavioural studies in the Nature Reserve 'Les Nouragues', French Guiana'. J Maps 12:26-32

Ringler E, Szipl G, Harrigan RJ, Bartl-Binder P, Mangione R, Ringler M (2018) Hierarchical decisionmaking balances current and future reproductive success. Mol Ecol 27:2289-2301

Roithmair ME (1994a) Male territoriality and female mate selection in the dart-poison frog Epipedobates trivittatus (Dendrobatidae, Anura). Copeia 1994:107-115

Roithmair ME (1994b) Field studies on reproductive behaviour in two dart-poison frog species (Epipedobates femoralis, Epipedobates trivittatus) in Amazonian Peru. Herpetol J 4:77-85

Rojas B (2014) Strange parental decisions: fathers of the dyeing poison frog deposit their tadpoles in pools occupied by large cannibals. Behav Ecol Sociobiol 68:551-559

Rojas B (2015) Mind the gap: treefalls as drivers of parental trade-offs. Ecol Evol 5:4028-4036

Rojas B, Pašukonis A (2019) From habitat use to social behavior: natural history of a voiceless poison frog, Dendrobates tinctorius. bioRxiv 515122

Ross C (2001) Park or ride? Evolution of infant carrying in primates. Int J Primatol 22:749-771

Schulte LM, Schulte R, Lötters S (2013) Avoiding predation: the importance of chemical and visual cues in poison frog reproductive behaviour. In: East ML, Dehnhard M (eds) Chemical signals in vertebrates 12. Springer, New York, pp 309-321

Silverstone PA (1975) A revision of the poison-arrow frogs of the genus Dendrobates Wagler. Nat Hist 21:1-55

Silverstone PA (1976) A revision of the poison-arrow frogs of the genus Phyllobates Bibron in Sagra (Family Dendrobatidae). Nat Hist 27:1-53

Sinsch U (2014) Movement ecology of amphibians: from individual migratory behaviour to spatially structured populations in heterogeneous landscapes. Can J Zool 92:491-502

Starrfelt J, Kokko H (2010) Parent-offspring conflict and the evolution of dispersal distance. Am Nat 175:38-49

Summers K (1990) Paternal care and the cost of polygyny in the green dart-poison frog. Behav Ecol Sociobiol 27:307-313

Summers K, McKeon CS (2004) The evolutionary ecology of phytotelmata use in Neotropical poison frogs. Misc Publ Univ Mich Mus Zool 193:55-73

Summers K, Tumulty J (2013) Parental care, sexual selection, and mating systems in Neotropical poison frogs. In: Macedo RH, Machado G (eds) Sexual selection: perspectives and models from the neotropics. Academic Press, London, pp 289-320

Vitale A, Calisi R, Carere C, Carter T, Ha JC, Hubrecht R, Jennings D, Metcalfe N, Ophir AG, Ratcliffe JM, Roth TC, Smith A, Sneddon L (2018) Guidelines for the treatment of animals in behavioural research and teaching. Anim Behav 135:I-X 
Wells KD (2007) The ecology and behavior of amphibians. The University of Chicago Press, Chicago Weygoldt P (1987) Evolution of parental care in dart poison frogs (Amphibia: Anura: Dendrobatidae). J Zool Syst Evol Res 25:51-67

Wolff JO, Huber SJ, Gorb SN (2015) How to stay on mummy's back: morphological and functional changes of the pretarsus in arachnid postembryonic stages. Arthropod Struct Dev 44:301-312

Publisher's Note Springer Nature remains neutral with regard to jurisdictional claims in published maps and institutional affiliations. 